\title{
Mancha de Septoria da Alface: Isolamento, Inoculação e Avaliação de Cultivares em Condições de Campo e Casa de Vegetação
}

\author{
Cristina S. Sousa' ${ }^{1}$, Warwick E. Kerr ${ }^{2}$, Marlos R. Santos ${ }^{1}$, Alcione S. Arruda ${ }^{1}$, Vanessa B. M. G. Spini ${ }^{3}$, \\ Fernando C. Juliatti ${ }^{1} \&$ Armando Takatsu'
}

${ }^{1}$ Instituto de Ciências Agrárias, Universidade Federal de Uberlândia, Campus Umuarama, CEP 98400-902, Uberlândia, MG, e-mail: cristsoares@ hotmail.com; ${ }^{2}$ Instituto Nacional de Pesquisa da Amazônia, CEP 69060-000, Cx. Postal 478; ${ }^{3}$ Departamento de Genética e Matemática Aplicada à Biologia, Faculdade de Medicina de Ribeirão Preto

(Aceito para publicação em 16/07/2003)

Autor para correspondência: Cristina Soares de Sousa

SOUSA, C.S., KERR, W.E., SANTOS, M.R., ARRUDA, A.S., SPINI, V.B.M.G., JULIATTI, F.C. \& TAKATSU, A. Mancha de Septoria da alface: isolamento, inoculação e avaliação de cultivares em condições de campo e casa de vegetação. Fitopatologia Brasileira 28:555-558. 2003.

\section{RESUMO}

Este trabalho teve como objetivo estabelecer metodologias adequadas para o isolamento e inoculação de Septoria lactucae e avaliação de nove cultivares de alface (Lactuca sativa), Vitória-de-SantoAntão, Uberlândia 10.000, Maioba, Elba, Aurélia, Black Seeded Simpson, Grand Rapids, Salad Bowl-Mimosa e Babá de Verão, quanto aos níveis de resistência à septoriose, em condições de casa de vegetação e campo. Os melhores resultados obtidos foram: a) para isolamento: transferência dos cirros de conídios diretamente para o meio de BDA com os antibióticos estreptomicina, cloranfenicol, ampicilina e rifampicilina; b) para inoculação: aspersão das plantas no estádio de seis a oito folhas com a suspensão de inóculo na concentração de 1 x $10^{4}$ conídios $/ \mathrm{ml}$, e manutenção em câmara úmida por 48 h. Houve diferenças significativas entre as cultivares testadas em casa de vegetação e em campo. Tanto em casa de vegetação quanto em teste de campo as cultivares Maioba e Vitória de Santo Antão foram avaliadas como a mais susceptível e a mais resistente, respectivamente. Diante desses resultados, a metodologia de casa de vegetaçãopode ser considerada como altamente promissora para a avaliação rápida de grande número de variedades ou materiais genéticos, nos trabalhos de melhoramento de alface para a resistência à S. lactucae.

Palavras-chave adicionais: Septoriose, Septoria lactucae, Lactuca sativa.

\section{ABSTRACT}

Lettuce Septoria leaf spot: isolation, inoculation, cultivar evaluation in field and greenhouse conditions

The objectives of this work were to establish appropriate methodologies for isolation and inoculation of Septoria lactucae in order to evaluate resistance. Nine lettuce (Lactuca sativa) cultivars (Vitória-de-Santo-Antão, Uberlândia 10.000, Maioba, Elba, Aurélia, Black Seeded Simpson, Grand, Rapids, Salad Bowl-Mimosa and Babá de Verão) were screened for resistance to this pathogen under greenhouse and field conditions. The best results obtained were: a) for isolation: to transfer cirrus of conidia directly to the surface of Petri dishes with PDA medium plus antibiotics (streptomycin, chloramphenicol, ampicilim and riphampicin); b) for inoculation: to spray plants of six to eight leaves with a conidia suspension of $1 \times 10^{4}$ spores $/ \mathrm{ml}$ and keep them in a moist chamber for $48 \mathrm{~h}$. Significant differences were found among cultivars both in greenhouse and field tests. Under both conditions the cultivars Maioba and Vitoria de Santo Antão were found to be, respectively, the most susceptible and the most resistant cultivars among those tested. From these results, the greenhouse test methodology is seen to ge highly promising for the rapid screening of a great number of genotypes in breeding programs of lettuce resistant to S. lactucae.
A septoriose causada pelo fungo Septoria lactucae Passerini é uma das doenças mais importantes que afetam a cultura da alface (Lactuca sativa L.), muito comum em regiões de clima ameno e em épocas chuvosas. As condições favoráveis para o desenvolvimento da doença são alta umidade e temperatura na faixa de $10 \mathrm{a} 28^{\circ} \mathrm{C}$. Sua importância deve-se às lesões necróticas no limbo foliar que prejudicam o valor comercial do produto. Nos campos de produção de sementes, a doença causa seca nas folhas devido a coalescência de muitas manchas, resultando em danos na formação das sementes. $\mathrm{O}$ fungo ataca principalmente as folhas, mas pode afetar também a haste e os órgãos florais, em campos de produção de sementes. Os sintomas nas folhas são manchas com contornos irregulares. O tecido afetado, inicialmente com aspecto desidratado, torna-se pardacento, com numerosos pontos de cor escura que são os corpos de frutificação do fungo. Esses corpos de frutificação são os picnídios, visíveis a olho nu. Quando em ambiente úmido, verifica-se na parte superior dos picnídios, uma massa de esporos (cirros) que só é liberada na presença de filme de água. Não havendo água, os conídios não germinam e dificilmente são disseminados pelo vento (Pavan \& Kurozawa, 1997). Segundo (Galli, 1980) existe uma correlação entre o progresso da doença e a ocorrência de condições ótimas para o desenvolvimento do patógeno, que se multiplica e se dissemina por meio de reprodução assexual.

Não há cultivares consideradas imunes a esta doença, 
mas em observações de campo pode-se verificar diferenças nos níveis de resistência horizontal.

O melhoramento das variedades visando o aumento do nível de resistência é de grande importância para o controle desta doença, tendo em vista que o uso de materiais mais resistentes aumenta proporcionalmente a eficiência de outras medidas aplicadas de maneira integrada. Dispor de metodologia para distinguir diferenças nos níveis de resistência das variedades ou nos materiais segregantes é condição fundamental para o trabalho de melhoramento.

Estudos que envolvem o controle deste fitopatógeno, em especial a avaliação de resistência em condições controladas, exigem grande quantidade de inóculo. Assim, é de primordial importância o uso de um meio de cultura que proporcione condições ideais para sua esporulação (Bertagnolli et al., 1988).

Este trabalho teve como objetivo, estabelecer metodologias adequadas para isolamento e inoculação de $S$. lactucae em condições de casa de vegetação para a avaliação de variedades ou cultivares de alface quanto à resistência ou suscetibilidade à septoriose.

Os experimentos para otimização do isolamento e preservação de $S$. lactucae foram realizados no laboratório de Fitopatologia da Universidade Federal de Uberlândia.

Para o isolamento do fungo foram utilizadas duas metodologias, a primeira, de transferência para o meio de cultura de uma pequena seção de 2 a $3 \mathrm{~mm}$ de tecido retirado da região de transição entre as áreas necrosada e sadia, previamente tratada com soluções de hipoclorito a 1\%, álcool a $70 \%$ e água esterilizada e a outra, de transferência de cirros de conídios que se formam sobre os picnídios diretamente para o meio de cultura, com o auxílio de uma lupa e uma agulha esterilizada. $\mathrm{O}$ meio de cultura BDA com os antibióticos sulfato de estreptomicina e ampicilina a $200 \mathrm{mg} / \mathrm{l}$, cloranfenicol a $50 \mathrm{mg} / \mathrm{l}$ e rifampicilina a $10 \mathrm{mg} / \mathrm{l}$ (adicionados após a esterilização) foi utilizado nas duas metodologias.

O fungo isolado da alface foi preservado pelo método de dessecação da colônia, adaptado do método de preservação de bactérias desenvolvido por Takatsu (1994). O fungo foi cultivado em meio de BDA ou de V8 em placa de Petri por 15 a 20 dias à temperatura ambiente. As colônias selecionadas foram embebidas com duas a três gotas da solução de gelatina e dextrose a 5\% (cada ingrediente foi esterilizado separadamente e misturados no momento do uso) e transferidas com espátula de aço flambada para placas de Petri descartáveis, com perfurações (12 a 15 furos de $2 \mathrm{~mm}$ no fundo da placa) e mantidas no dessecador com sílica gel durante dez a 15 dias. Para evitar que as culturas do fungo ficassem aderidas à placa, elas foram colocadas sobre um suporte de tela de metal recortado de tamanho adequado para a placa e a colônia do fungo colocada sobre este suporte.

As colônias dessecadas foram transferidas para envelopes de papel e alumínio e mantidas na geladeira dentro de vidro de boca larga e tampa de pressão, contendo sílica gel.

Para a recuperação do fungo, foram retiradas, com pinça ou alicate de unha flambados, pequenas lascas das colônias dessecadas e transferidas para o meio de cultura.

No experimento em casa de vegetação, a inoculação foi utilizada por aspersão da suspensão de inóculo na concentração de 1 x $10^{4}$ conídios por ml, em plantas cultivadas em vasos, no estádio de seis a oito folhas, A escolha desta concentração foi baseada nos dados obtidos por Malnati et al. (1990) e Marchi et al. (2001) com Septoria lycopersici em tomateiro (Lycopersicon esculentum Mill.) e Dias (1990) com Septoria passiflorae em maracujazeiro (Passiflora edulis Sims f. flavicarpa Deg). A testemunha foi pulverizada apenas com água e as plantas assim tratadas foram mantidas em condições de câmara úmida (cobertas com sacos plásticos) por $48 \mathrm{~h}$ e depois, esta condição foi mantida somente à noite até o aparecimento de sintomas.

Foram utilizados vasos com capacidade para 1,51 preenchidos com uma mistura de solo com areia na proporção de 2:1 e adubo orgânico. Esta mistura foi tratada com brometo de metila na dosagem de $40 \mathrm{~cm}^{3} / \mathrm{m}^{3}$ de solo.

Foram avaliadas nove cultivares (Vitória de Santo Antão, Uberlândia 10.000, Maioba, Elba, Aurélia, Black Seeded Simpson, Gram Rapids, Salad Bowl-Mimosa e Babá de Verão), em um delineamento de parcelas inteiramente casualizadas, com quatro repetições. As avaliações foram feitas pela contagem do número de folhas com sintomas no $11^{\circ}$ dia após a inoculação e pelo nível de severidade aos 11, 13, 15 e 17 dias após a inoculação, utilizando-se uma escala de notas de 1 a 4 em função do grau de severidade visual das folhas, sendo nota $1=1$ a $25 \%$ da folha com sintoma, nota $2=26$ a $50 \%$, nota $3=51$ a $75 \%$, nota $4=76$ a $100 \%$ ).

Foram efetuados os testes de normalidade (Shapiro-Wilk) e homogeneidade (Bartlett). Posteriormente, fez-se análise da variância com teste de Tukey mediante a utilização dos valores obtidos a partir das observações da severidade da doença.

$\mathrm{O}$ experimento em condições de campo foi desenvolvido na área experimental do Instituto de Ciências Agrárias da Universidade Federal de Uberlândia.

A temperatura mínima variou de 18 a $20^{\circ} \mathrm{C}$, e a máxima de 28 a $34^{\circ} \mathrm{C}$, durante o período de realização do experimento; a umidade relativa variou de 77 a $96 \%$, e a precipitação de 4 a $96,5 \mathrm{~mm}$.

As cultivares de alface foram as mesmas avaliadas em condições de casa de vegetação. As mudas produzidas em bandejas de 200 células foram transplantadas aos 20 dias, quando apresentavam quatro a seis folhas definitivas, para canteiros adubados com esterco de curral e superfosfato simples. Foram efetuadas três adubações com uréia $\left(10 \mathrm{~g} / \mathrm{m}^{2}\right)$ aos dez, 20 e 30 dias.

O delineamento experimental utilizado foi o de blocos casualizados, com nove tratamentos e três repetições. As parcelas foram constituídas pelas cultivares plantadas no espaçamento de $0,30 \times 0,25 \mathrm{~m}$, totalizando seis plantas.

A inoculação foi realizada 13 dias após o transplante das mudas para o canteiro. O inóculo foi obtido a partir de folhas com sintomas da doença, coletadas na Escola Agrotécnica Federal de Uberlândia, as quais foram trituradas com água em liquidificador, e a suspensão aplicada nas plantas. 
Mancha de Septoria da alface: isolamento, inoculação e avaliação de...

As avaliações foram feitas pelo nível de severidade aos 11, 13, 19 e 23 dias após a inoculação, utilizando-se uma escala de notas de 1 a 4 em função do grau de severidade visual das folhas, sendo nota $1=1$ a $25 \%$ da folha com sintoma; nota $2=26$ a $50 \%$; nota $3=51$ a $75 \%$ e nota $4=76$ a $100 \%$, e pelo cálculo da área abaixo da curva de progresso da doença.

Foram efetuados os testes de normalidade (ShapiroWilk) e homogeneidade (Bartlett). Posteriormente, fez-se análise da variância com teste de Tukey mediante a utilização dos valores obtidos a partir das observações da severidade da doença, e dos valores obtidos por meio do cálculo da área abaixo da curva de progresso da doença.

Para o isolamento de $S$. lactucae, somente o método de transferência de cirros apresentou resultado satisfatório, sem a contaminação com outros fungos. A utilização dos quatro antibióticos não inibiu o crescimento do patógeno e permitiu o isolamento livre de contaminação com bactérias.

O fungo recuperado de colônias preservadas por dessecação não apresentou nenhuma variação durante todo o período em que foi utilizado. O método é simples, prático mas exige boa assepsia, sendo necessário o uso da câmara de fluxo laminar.

A concentração de inóculo de $1 \times 10^{4}$ conídios $/ \mathrm{ml}$ utilizado neste experimento, com base nos dados de Marchi $e t$ al. (2001), Malnati et al. (1992) e Dias (1990) foi também eficiente para avaliar os níveis de tolerância das cultivares de alface estudadas.

No experimento em casa de vegetação, o método de contagem do número de folhas com sintomas não revelou diferenças significativas entre as cultivares (Tukey a 1\%). Porém pelo nível de severidade foi possível distinguir diferenças entre as cultivares na leitura efetuada aos 13 dias após a inoculação (Tabela 1).

Nas avaliações feitas em condições de campo pelo nível de severidade foi possível distinguir as diferenças entre as cultivares na leitura efetuada no $23^{\circ}$ dia após a inoculação, com teste de Tukey a 5\% (Tabela 1). Utilizando-se os valores da área abaixo da curva de progresso da doença, pôde-se observar diferenças significativas na evolução da doença entre as cultivares avaliadas (Tabela 2).

Tanto em condições de casa-de-vegetação quanto em condições de campo a cultivar Maioba, considerada como uma cultivar com alta susceptibilidade em condições de campo (Santos, 1996), apresentou a maior média, enquanto a cultivar Vitória-de-Santo-Antão, foi, nas condições climáticas de Uberlândia, a mais resistente nas três análises feitas, havendo diferença significativa entre estas duas cultivares, tanto para avaliação da severidade quanto para a área abaixo da curva de progresso da doença. A cultivar Uberlândia 10.000 não diferiu significativamente da cultivar Maioba nas análises feitas em casa de vegetação, utilizando o nível de severidade da doença e em campo utilizando o cálculo da área abaixo da curva de progresso da doença. Quando analisado o nível de severidade da doença, em campo, essa cultivar diferiu significativamente da cultivar Maioba e das cultivares com menor média (Vitória de Santo Antão, Babá e Mimosa). Visto que a cultivar Uberlândia
TABELA 1 - Notas médias de severidade da septoriose em cultivares de alface (Lactuca sativa), nos $13^{\circ}$ e $23^{\circ}$ dias após a inoculação em condições de casa de vegetação e no campo, respectivamente

\begin{tabular}{|c|c|c|}
\hline \multirow{2}{*}{ Coltivar } & \multicolumn{2}{|c|}{ Médias" } \\
\hline & Casa de Vegretaçāo & Campo \\
\hline Masiplat & $2.63 \mathrm{a}$ & 3.2427 is \\
\hline Filbu & $2: 12$ alt & $2.9366 \mathrm{~b}$ \\
\hline l!lserlârsdia 10_0400 & 2,194 alt & $2,9027 \quad b$ \\
\hline Ciratal Rappilse & 1,85 all & $2.7388 \mathrm{bc}$ \\
\hline Aurelial & 1,84 altec & 2,6827 bc \\
\hline [3lack Seeded Simprsom & 1,70 abce & 2,6766 be \\
\hline Salad Bowl-Mimosa & $1,50 \mathrm{bc}$ & 2,4922 sde \\
\hline Baba de Verāo & 1,30 be & 2,2705 de \\
\hline Vitória de Santo Antēo & 1.000 & 2,0550 \\
\hline $\mathrm{CVLV}=22.48 \%$ & Drmáx $=0.19$ & $\mathrm{~W}=0.96$ \\
\hline CVLampar $10,231 / 1$ & $B=15,00$ & $\beta=4.32$ \\
\hline
\end{tabular}

*Médias seguidas de mesma letra não diferem entre si em nível de 5\%, segundo o teste de Tukey. Dmáx: estatística do teste de Kolmogorov; B: estatística do teste de Bartlett; W: estatística do teste de ShapiroWilk.

TABELA 2 - Médias obtidas pelo cálculo da área abaixo da curva de progresso da septoriose das cultivares de alface (Lactuca sativa) avaliadas

\begin{tabular}{|c|c|}
\hline Coltivar & Médla* \\
\hline Majoba & 39,24 i \\
\hline Éllsa & 38,39 alt \\
\hline Utertlûndian 10,000 & 37,11 ata: \\
\hline Aurólia & 31,04 bod \\
\hline Grand Rapsds & $33,9 \mathrm{~s}$ bod \\
\hline Simpricitr & $3.3,41$ \\
\hline Mimuss; & 31,13 \\
\hline Babá de Verão & 30,71 \\
\hline Vitorsa-de-Sanco-Antāo & 27,88 \\
\hline$C V-4.95$ & $\begin{array}{l}W=0,8674 \\
\beta=24,959\end{array}$ \\
\hline
\end{tabular}
segundo teste de Tukey. W: estatística do teste de Shapiro-Wilk; B: estatística do teste de Bartlett.

10.000 é de grande interesse, devido ao seu alto teor de vitamina A (10.200 U.I./100 g de folha), pode-se sugerir que seja feito um retrocruzamento com o seu parental feminino (Vitória de Santo Antão), visando aumentar sua resistência à septoriose.

Pelos resultados obtidos, a metodologia de avaliação, em casa de vegetação, pode ser considerada como altamente promissora para a avaliação rápida de grande número de cultivares, nos trabalhos de melhoramento de alface para resistência à septoriose.

\section{REFERÊNCIAS BIBLIOGRÁFICAS}

BERTAGNOLLI, P.F., REIS, E.M., \& PORTO, M.D.M. Influência de meios de cultura e períodos de crescimento na esporulação de Septoria glycines. Pesquisa Agropecuária Brasileira 23:869-875. 1998. 


\section{C.S. Sousa et al.}

DIAS, S.C. Morte precoce do maracujazeiro amarelo (Passiflora edulis f. flavicarpa) causada por patógenos que afetam a parte aérea da planta. (Tese de mestrado). Brasília. Universidade de Brasília, 1990.

GALLI, F. Manual de fitopatologia. Doenças das plantas cultivadas. São Paulo: Agronômica Ceres, 1980.

MALNATI, W.D., INQUE, A.K. \& REIFSCHNEIDER, F.J.B. Efeito da concentração de inóculo na avaliação de resistência de tomate à Septoria lycopersici. Fitopatologia Brasileira 15:147. 1990. (Resumo).

MARCHI, C.E., BORGES, M.F. \& REIS, S.N. Meios de cultura para rápida e abundante esporulação de Septoria lycopersici. Summa
Phytopathologica 27:83-85. 2001.

SANTOS, C.A.P. Contribuições à genética e melhoramento de alfaces mediante cruzamentos e cultura de tecidos. (Tese de mestrado). Uberlândia. Universidade Federal de Uberlândia. 1996.

TAKATSU, A. Coleção de bactérias fitopatogênicas preservadas pelo método de dissecação em tirinhas de papel:informações de dez anos. Fitopatologia Brasileira 19:315. 1994. (Resumo).

PAVAN, M. A. \& KUROZAWA. C. Doenças da alface. In: Kimti, H. \& Amorim, L. (Eds.) Manual de Fitopatologia, vol.2, São Paulo:Editora Ceres. 1997. 